\title{
Preterm babies grown up: understanding a hidden public health problem
}

\author{
M. P. G. Allin* \\ King's College London, Institute of Psychiatry, Department of Psychological Medicine and Psychiatry, London, UK
}

Even when they have grown up, the survivors of preterm birth are at increased risk of psychiatric illness. As the incidence of preterm birth is increasing, there is now a growing population of adults whose mental health needs have been neglected.

Received 18 March 2009; Accepted 18 March 2009; First published online 29 April 2009

Key words: Adolescence, neurodevelopment, preterm birth.

\section{Introduction}

Our species has an unusually long gestation period compared to other primates, possibly related to the evolution of our particularly large brain. Human gestation is normally reckoned to take between 38 and 42 weeks: we refer to babies born at 37 weeks and earlier as 'preterm'; those born at 32 weeks or less as 'very preterm'; and those born at less than 26 weeks as 'extremely preterm'. Preterm birth is a hidden public health problem in the western world, and one that has so far proved hard to prevent. Indeed, its incidence seems to be on the rise, at least in the USA, where it increased from $9.5 \%$ of births in 1981 to $12.7 \%$ in 2005 (Goldenberg et al. 2008). This results in a considerable economic burden; neonatal care for preterm infants costs around US $\$ 5.8$ million a year in the USA (Russell et al. 2007). The continuing care of pretermborn individuals is more costly still, with estimates ranging from $€ 65$ million per year in Sweden (Lindström et al. 2007) to US $\$ 26.2$ billion in the USA (Allen, 2008). Why so expensive? Preterm birth is associated with physical, cognitive and behavioural problems, particularly for those born at younger gestational ages ( $\leqslant 32$ weeks). These difficulties may impair education, and require ongoing health and social care. One major consequence of very preterm and extremely preterm birth is injury to the immature brain, which is particularly vulnerable to hypoxia and the other adverse conditions that these neonates encounter in their first weeks outside the womb. Studying the interaction between these early brain injuries and subsequent neurodevelopment is beginning to

* Address for correspondence: Dr M. P. G. Allin, Box 63

Institute of Psychiatry, De Crespigny Park, London SE5 8AF, UK.

(Email : matthew.allin@iop.kcl.ac.uk) provide new insights into the psychiatric problems suffered by this population.

\section{Preterm birth and adult psychiatric outcome}

Disabilities including cerebral palsy, learning disability and sensory deficits are increased in children born preterm. These complications are more likely in those born at younger gestational ages (FoulderHughes \& Cooke, 2003), but even taking the most pessimistic estimate, $80-90 \%$ of survivors of preterm birth will not suffer major disabilities (Powls et al. 1995). However, they may still go on to experience milder degrees of neurodevelopmental impairment later in life, and tend to do less well at school than their term-born classmates (Saigal \& Doyle, 2008).

Various population and case-control studies have indicated associations between obstetric complications (which include preterm birth) and adult psychiatric illness. For example, the link between schizophrenia and obstetric complications is well established (Cannon et al. 2002; Walshe et al. 2005). Preterm birth has also been implicated as an aetiological factor in depressive disorder, attention deficit hyperactivity disorder and anorexia nervosa (Cnattingius et al. 1999; Thompson et al. 2001; Patton et al. 2004; Saigal \& Doyle, 2008). What is less clear is the extent to which populations of preterm-born individuals are at risk of psychiatric problems as they grow up.

Two broad approaches have been used to begin to address this question. The first is made feasible by the incomparable population data available in certain Scandinavian countries, allowing the cross-linking of databases of perinatal complications and psychiatric outcome 20 or more years later. This method can call on very large numbers of subjects and is 
epidemiologically robust. Lindström et al. (2009) performed just such a study, using over half a million Swedish birth records. Preterm birth was associated with an increased risk of being hospitalized for a psychiatric illness in adulthood. The risk was greater for those with the severest degrees of prematurity (24-28 weeks), although, as the authors make clear, the majority of those hospitalized had 'moderate' preterm birth (29-32 weeks). The second approach is to take a population of children born preterm and follow them until they have grown up. As can be imagined, this is a tall order! Such approaches can tell us about the social, psychological and biological factors that influence the risk of psychiatric illness. For example, there is now some evidence to suggest that very preterm adults have altered personality styles, with reduced extraversion (Allin et al. 2006), reduced propensity to take risks (Hack et al. 2007) and increased behavioural inhibition (Pyhälä et al. 2009). The origin of such personality differences may include genetic predispositions, the effect of mild cognitive impairments, parenting style, and negative experiences in school or with peers, or, more likely, a combination of all these factors. There is also some evidence that very preterm adults are more likely to suffer from anxiety and depression and associated 'common mental disorders' (Walshe et al. 2008). This risk is elevated further in preterm individuals who also have a family psychiatric history, suggesting an interaction between genetic inheritance and perinatal adversity.

\section{The role of brain development in adolescence}

Along with long gestation, another prominent feature of development in our species is our long period of adolescence, during which time our cognitive and social capabilities mature. Adolescence is also the period when many psychiatric disorders begin to manifest. Does being born preterm affect brain development during this sensitive period? Longitudinal magnetic resonance imaging (MRI) scanning studies have started to address this.

In a follow-up of individuals born at a London teaching hospital, my colleagues and I scanned two groups (one born very preterm, one born at term) at age 14 years and then again at 19 years using structural MRI. Both groups had similar overall trajectories of grey and white matter change over this time (Parker et al. 2008), with grey matter volume decreasing in both groups and white matter volume increasing. Such patterns are often taken to indicate synaptic pruning in grey matter and ongoing myelination in white matter, although the exact tissue correlates of MRI changes are not yet known. We also examined two brain structures that are known to be affected by preterm birth: the cerebellum (also of interest because of its role in coordinating thought and affect) and the corpus callosum (involved in integration of information between cerebral hemispheres). Here we found interesting deviations from the expected growth trajectories. First, the cerebellum decreased in the very preterm group between adolescence and adulthood (in the term group it did not change). This cerebellar decrement was associated with worse self-rated mental health (Parker et al. 2008). Second, there was dramatic growth of the corpus callosum in the very preterm group. Again, this change had functional consequences in the preterm group, this time beneficial; greater corpus callosum growth was associated with higher IQ at 19 years (Allin et al. 2007).

A tentative explanatory model consistent with these observations is that the growth of the corpus callosum represents a plastic response to a deficit of development that includes (but may not be limited to) the cerebellum. In this model, networks that include the cerebellum fail to develop adequately to meet the cognitive and social demands of the adolescentadult transition. This is detrimental, and is associated with poorer mental health. The corpus callosum growth then represents a plastic response, increasing brain connectivity to mitigate the functional effects of this cerebellar deficit, for example by optimizing cognitive function.

In summary, very preterm birth is a risk factor for a variety of adult psychiatric illnesses. This may in part be related to altered trajectories of brain maturation during the 'sensitive period' of adolescence. A lot of work remains to be done, both in identifying which other brain structures also have altered developmental trajectories and which do not, and in clarifying the effects of genes, environment and experience on adolescent development. Studying longitudinal cohorts in this way can help us to understand how neurodevelopment is involved in psychiatric illness. It should also enable us to provide appropriate support to enable preterm babies to grow up into healthy adults.

\section{Declaration of Interest}

None.

\section{References}

Allen MC (2008). Neurodevelopmental outcomes of preterm infants. Current Opinion in Neurology 22, 123-128.

Allin MPG, Nosarti C, Narberhaus A, Walshe M, Frearson S, Wyatt J, Rifkin L, Murray RM (2007). Growth of the corpus callosum in adolescents born preterm. Archives of Pediatrics and Adolescent Medicine 161, 1183-1189. 
Allin MPG, Rooney M, Cuddy M, Wyatt J, Walshe M, Rifkin L, Murray RM (2006). Personality in young adults who are born preterm. Pediatrics 117, 309-316.

Cannon M, Jones PB, Murray RM (2002). Obstetric complications and schizophrenia: historical and meta-analytic review. American Journal of Psychiatry 159, 1080-1092.

Cnattingius S, Hultman CM, Dahl M, Sparen P (1999). Very preterm birth, birth trauma, and the risk of anorexia nervosa among girls. Archives of General Psychiatry 56, 634-638.

Foulder-Hughes LA, Cooke RWI (2003). Motor, cognitive and behavioural disorders in children born very preterm. Developmental Medicine and Child Neurology 45, 97-103.

Goldenberg R, Culhane J, Iams J, Romero R (2008). Epidemiology and causes of preterm birth. Lancet 371, 75-84.

Hack M, Cartar L, Schluchter M, Klein N, Forrest C (2007). Self-perceived health, functioning and well-being of very low birth weight infants at age 20 years. Journal of Pediatrics 151, 635-641.

Lindström K, Lindblad F, Hjern A (2009). Psychiatric morbidity in adolescents and young adults born preterm: a Swedish national cohort study. Pediatrics 123, e47-e53.

Lindström K, Winbladh B, Haglund B, Hjern A (2007). Preterm infants as young adults: a Swedish national cohort study. Pediatrics 120, 70-77.

Parker J, Mitchell A, Kalpakidou A, Walshe M, Yeon-Jung H, Nosarti C, Santosh P, Rifkin L, Wyatt J, Murray RM, Allin MPG (2008). Cerebellar growth and behavioural and neuropsychological outcome in preterm adolescents. Brain 131, 1344-1351.
Patton GC, Coffey C, Carlin JB, Olsson CA, Morley R (2004). Prematurity at birth and adolescent depressive disorder. British Journal of Psychiatry 184, 446-447.

Powls A, Botting N, Cooke RWI, Marlow N (1995). Motor impairments in children 12 to 13 years old with a birthweight less than $1250 \mathrm{~g}$. Archives of Disease in Childhood 72, F62-F66.

Pyhälä R, Räikkönen K, Pesonen A-K, Heinonen K, Hovi P, Eriksson JG, Järvenpää A-L, Andersson S, Kajantie E (2009). Behavioral inhibition and behavioral approach in young adults with very low birth weight: the Helsinki study of very low birth weight adults. Personality and Individual Differences 46, 106-110.

Russell RB, Green NS, Steiner CA, Meikle S, Howse JL, Poschman K, Dias T, Potetz L, Davidoff MJ, Damus K, Petrini JR (2007). Cost of hospitalization for preterm and low birth weight infants in the United States. Pediatrics 120, e1-e9.

Saigal S, Doyle LW (2008). An overview of mortality and sequelae of preterm birth from infancy to adulthood. Lancet 371, 261-269.

Thompson C, Syddall H, Rodin I, Osmond C, Barker DJ (2001). Birth weight and the risk of depressive disorder in late life. British Journal of Psychiatry 179, 450-455.

Walshe M, McDonald C, Taylor M, Zhao J, Sham P, Grech A, Schulze K, Bramon E, Murray RM (2005). Obstetric complications in patients with schizophrenia and their unaffected siblings. European Psychiatry 20, 28-34.

Walshe M, Rifkin L, Rooney M, Healy E, Fern A, Wyatt J, Murray RM, Allin MPG (2008). Psychiatric disorder in young adults born very preterm: role of family history. European Psychiatry 23, 527-531. 